\title{
Iron ore pellet disintegration mechanism in simulated shaft furnace conditions
}

Lingyun Yi, Zhucheng Huang*, Tao Jiang, Ronghai Zhong, Zhikai Liang

School of Minerals Processing and Bioengineering, Central South

University, Changsha 410083, PR China

* Corresponding authors, E-mail: zchuangcsu@126.com (Zhucheng

Huang), jiangtao@csu.edu.cn (Tao Jiang). Address: School of Minerals

Processing and Bioengineering, Central South University, Changsha 410083, PR China. Tel./Fax: +86 73188830542. 
Abstract: The disintegration behavior and mechanism of iron ore pellet in simulated shaft furnace conditions were investigated in details. Effects of temperature, reducing gas and gangue compositions were emphatically discussed. It was found that pellet disintegrated acutely as reduced by $\mathrm{H}_{2} / \mathrm{CO}=0.8$ at $550{ }^{\circ} \mathrm{C}$. Gangue minerals in pellet were proved to ease the disintegration in various degrees. $\mathrm{SiO}_{2}$ or $\mathrm{CaO}$ could remarkably lower reduction disintegration index (RDI). But the effect of $\mathrm{MgO}$ or $\mathrm{Al}_{2} \mathrm{O}_{3}$ was much weaker. Furthermore, intrinsic relation between disintegration and reduction was revealed from microstructure aspect. Results demonstrated that lattice transition stress and crack generation brought about by the low temperature reduction led to pellet structure failure and therefore disintegration. The reduction degree showed positive correlation with disintegration level of pellet. Low melting point phase formed by $\mathrm{SiO}_{2}$ or $\mathrm{CaO}$ lessened crack formation in pellet. However, $\mathrm{MgO}$ or $\mathrm{Al}_{2} \mathrm{O}_{3}$ could not play a similar role.

Keywords: Iron ore pellet, Gas-based reduction, Disintegration behavior, Shaft furnace, Hydrogen, Carbon monoxide 


\section{Introduction}

Approximately $10 \%$ of anthropogenic $\mathrm{CO}_{2}$ emissions in the world derive from the iron and steel industry $[1,2]$. However, the fossil fuel energy (especially coke), performs as heat source, reducing agent and skeleton in blast furnace (BF), is essential to the conventional ironmaking process. Take $\mathrm{H}_{2}$ as the substitution for coal in BFs may be a potential solution to overcome this problem. For the partial use of $\mathrm{H}_{2}$ (rest is $\mathrm{CO}$ ), shaft furnace direct reduction process (such as Midrex and HYL-III) has become the focus in ironmaking research field [3-6]. But the reduction disintegration of furnace burden at low temperature, exists both in BF and shaft furnace processes, strongly affects the permeability and thus the stable operation [2, 7-9]. Therefore, a better understanding of iron ore pellet disintegration behavior in shaft furnace is urgently required.

It is well known that disintegration of burdens always occurs around $500-600{ }^{\circ} \mathrm{C}$ in the upper zone of blast furnace. The main cause for disintegration is lattice expansion of iron oxide phase, due to its reduction from hematite to magnetite [9-14]. But hematite with different morphology effects variously. Large cracks usually form at reduced skeletal hematite along with net-like fine cracks near the reduced hematite. Therefore, approximately $30 \%$ of reduction disintegration index (RDI) for skeletal hematite was reported $[2,7,15-17]$. An appropriate increase in basicity $\left(\mathrm{CaO} / \mathrm{SiO}_{2}\right)$ or $\mathrm{MgO}$ addition improves resistance to reduction disintegration for their strength rise effect on burdens $[18,19]$. In some cases, increasing the $\mathrm{FeO}$ content of sinter also improves reduction disintegration by lessening the hematite reduction to magnetite 
[20]. But limestone addition or $\mathrm{TiO}_{2}$-rich materials exhibits poor reduction disintegration properties $[8,21]$. Generally, the RDI for sinter reduced by $\mathrm{CO}$ is always higher than that of the sinter processed by $\mathrm{H}_{2}$ at the same reduction degree. Reduction by $\mathrm{CO}$ gas leads to the formation of magnetite phases with not only long-thick but also fine cracks near the surface, opposite to that of $\mathrm{H}_{2}$ reduction (small amounts of fine cracks) $[2,7,15,22]$. And therefore lower burden strength in $\mathrm{CO}$ reduction.

An X-ray imaging technology was applied to the real-time observation of iron ore disintegration behavior [23]. It is found that cracks always initiate from pores and propagate through neighboring pores. And the crack initiation temperature is as low as $450{ }^{\circ} \mathrm{C}$. Spraying $\mathrm{CaCl}_{2}$ solution onto the burden surface to hinder the reducing gas diffusion is a common method for reduction disintegration prevention [24]. However, the $\mathrm{Cl}^{-}$ions introduced by $\mathrm{CaCl}_{2}$ also bring series of troubles to $\mathrm{BF}$ operation and environmental pollution [25].

It can be noticed that only few researchers studied disintegration of iron ore pellets during low temperature reduction with $\mathrm{H}_{2}-\mathrm{CO}$ mixtures, especially for the gas-based shaft furnace conditions. So, in the present work disintegration behavior of iron ore pellets in $\mathrm{H}_{2}-\mathrm{CO}$ mixtures was studied by simulating the upper part of shaft furnace. And mechanisms were also revealed, which was hoped to provide fine guidance to the practical operation of shaft furnace direct reduction process.

\section{Experimental}




\subsection{Materials}

Iron ore pellet sample supplied by a domestic pelletizing plant (China) was used as furnace burden in this work. The elemental composition of iron ore pellets was shown in Table 1. And the charged pellets were in the size range of $12.5-16 \mathrm{~mm}$ with average crushing strength of $2973 \mathrm{~N} /$ pellet.

\section{Table 1 Chemical composition of iron ore pellet}

Fig.1 presented the morphology of iron ore pellets used in this research. Image analysis showed that hematite was the major phase in the pellet. Plenty of plate-like hematite crystallized well and pores distributed in the connected hematite crystals uniformly.

Fig.1 Morphology of iron ore pellet sample, a-optical microscope image of cross section,

$$
\text { b-SEM micrographs of fractured surfaces, } \mathrm{H}=\text { hematite, } \mathrm{P}=\text { pore }
$$

High purity $(99.99 \%) \mathrm{H}_{2}, \mathrm{CO}, \mathrm{CO}_{2}$ and $\mathrm{N}_{2}$ were used as experimental gas. The reducing gases in the upper part of shaft furnace (vol.\% $\left(\mathrm{H}_{2}+\mathrm{CO}\right)=70 \%$, vol.\% $\left.\left(\mathrm{CO}_{2}+\mathrm{N}_{2}\right)=30 \%\right)$ were mixtures of $\mathrm{H}_{2}, \mathrm{CO}, \mathrm{CO}_{2}$ and $\mathrm{N}_{2}$ with various proportions by simulating coal gasification gas (No.2), Midrex gas (No.3) and HYL-II gas (No.4) respectively as shown in Table $2[12,13,26]$. 
Table 2 Composition of reducing gases

\subsection{Methods}

The schematic diagram of experimental apparatus and gas flow system used in this study were presented in Fig. 2. Iron ore pellets were reduced at $450-600{ }^{\circ} \mathrm{C}$ under

load of $0.4 \mathrm{~kg} / \mathrm{cm}^{2}$ by simulating upper shaft furnace conditions [27, 28]. For each reduction experiment, iron ore pellets were heated to the required temperature and then reduced for $60 \mathrm{~min}$ in reducing gases (listed in Table 2) at flow rate of $0.6 \mathrm{~m}^{3} / \mathrm{h}$. Subsequently, the reduced samples were cooled to room temperature in atmosphere of nitrogen. The reduction degree (RD) was evaluated as Eq. (1).

$$
\mathrm{RD}=\left(\mathrm{W}_{0}-\mathrm{W}_{1}\right) / \mathrm{W}_{2} \times 100 \%
$$

Where $\mathrm{W}_{0}$ and $\mathrm{W}_{1}$ were the weights of the sample before and after reduction respectively and $\mathrm{W}_{2}$ was the total possible weight loss due to the oxygen removal in the pellet.

Fig.2 Schematic diagram of the reduction apparatus,

1-load, 2-electric furnace, 3-graphite crucible, 4-pellets, 5-thermocouple, 6-graphite pusher, 7-gas mixer, 8-flowmeter, 9-cylinder

Disintegration tests were conducted on the reduced samples based on Chinese industrial standards (GB/T13242-91), using a tumbling drum with an inner diameter of $130 \mathrm{~mm}$ and length of $200 \mathrm{~mm}$, at a rotation speed of $30 \mathrm{rpm}$ for $10 \mathrm{~min}$. Then, the 
sample was sieved with a $3.15 \mathrm{~mm}$ mesh. Finally, the reduction disintegration index (RDI) value was calculated by Eq. (2).

$$
\mathrm{RDI}_{<3.15 \mathrm{~mm}}=\left(1-\mathrm{W}_{3} / \mathrm{W}_{4}\right) \times 100 \%
$$

Where $\mathrm{W}_{3}$ was the weight of particles larger than $3.15 \mathrm{~mm}$ and $\mathrm{W}_{4}$ was the weight of reduced sample before drum test.

The morphology (cross section) of reduced sample was observed by electron microscopy (Leica DMRXP). Cracks in every vision field were distinguished and counted by the equipped image analysis software (Qwin). The crack distribution (CD) was defined by Eq. (3). And Scanning Electron Microscope (FEI Quanta-200) was also applied to analyze the microstructure transformation of reduced samples.

$\mathrm{CD}=\mathrm{Ac} / \mathrm{At} \times 100 \%$

Where Ac was the area occupied by cracks in the vision field and At was the total area.

\section{Results and discussion}

\subsection{Effect of temperature}

The reduction disintegration indexes (RDIs) of pellets reduced at different temperatures was given in Fig.3. It can be seen from the line chart, the iron ore pellets adopted in this research showed good quality for anti-disintegration at low temperatures. The RDI of pellet fluctuated within a range of $0.4 \%$ to $3.2 \%$. In general, RDI increased steadily with temperature, peaking at $550{ }^{\circ} \mathrm{C}$, then presented a downward trend to $600{ }^{\circ} \mathrm{C}$. However it cannot be ignored that the RDI difference 
among pellets reduced by $\mathrm{CO}, \mathrm{H}_{2}$ and $\mathrm{H}_{2}-\mathrm{CO}$ mixtures as displayed in Fig. 3. And it would be discussed deeply in the section 3.2.

Fig.3 Effect of temperature on reduction disintegration index,

$1-\mathrm{CO}, 2-\mathrm{H}_{2} / \mathrm{CO}=0.8,3-\mathrm{H}_{2} / \mathrm{CO}=1.6,4-\mathrm{H}_{2} / \mathrm{CO}=2.6,5-\mathrm{H}_{2}$

The lattice structure transformation of $\mathrm{Fe}_{2} \mathrm{O}_{3}$ to $\mathrm{Fe}_{3} \mathrm{O}_{4}$ and consequent stress generation was considered to be the root cause of reduction disintegration at low temperature. Temperature rise, on one hand, intensified this stress because of the more reduction of $\mathrm{Fe}_{2} \mathrm{O}_{3}$ and therefore worsen the RDI. Fig. 4 showed this positive correlation between RDI value and reduction degree of pellets in our experiment obviously. On the other, the plasticity which determined the stress bearing property of pellets also increased with temperature. So, the disintegration of pellets displayed a weakening trend as temperature further rise to $600{ }^{\circ} \mathrm{C}$ not surprisingly (shown in Fig. 3). Wu et al. [9] studied the low temperature reduction disintegration properties of sinter, pellet and lump ore for BF process also concluded that RDIs deteriorated seriously at $550{ }^{\circ} \mathrm{C}$.

Fig.4 Relationship between RDI value and reduction degree

Microstructure (cross section) of reduced samples at $500{ }^{\circ} \mathrm{C}, 550{ }^{\circ} \mathrm{C}$ and $600{ }^{\circ} \mathrm{C}$ (reduced by $\mathrm{H}_{2} / \mathrm{CO}=0.8$ ) were characterized, as shown in Fig. 5, to reveal the intrinsic influence of temperature. 
Fig.5 SEM images of samples reduced at low temperatures, $a \& b-500^{\circ} \mathrm{C}, \mathrm{c} \& d-550^{\circ} \mathrm{C}$, e\&f- $600^{\circ} \mathrm{C}$

As can be seen from Fig.5 (a) and (b), pellet reduced at $500{ }^{\circ} \mathrm{C}$ retained nearly intact structure. The plate-like magnetite (bright) formed by reduction at $500{ }^{\circ} \mathrm{C}$ connected fully without obvious defect. It was this structure feature ensured its strength and therefore nice anti-disintegration property. However, the situation differed widely in the case of $550{ }^{\circ} \mathrm{C}$. Cracks were found in the reduced sample as shown in Fig.5 (c). Cracks generated initially from the pores (dark) and then extended to the magnetite zone. Due to the presence of pores, reducing gas was more likely to contact the surrounding hematite through them and produced cracks by reduction. Then reducing gas continued to diffuse along the crack and react with hematite, which promoted the expansion of crack and severe disintegration eventually. At the same time, fracted magnetite grains with fine cracks also formed in large quantities (Fig.5 (d)) for the lattice transformation stress. It further intensified the disintegration of pellets during reduction at $550{ }^{\circ} \mathrm{C}$. However, no extensive crack had been found in pellets reduced at $600{ }^{\circ} \mathrm{C}$ as presented in Fig.5 (e). Maybe the temperature rise enhanced plasticity of binder and slag phase in pellet, which avoided severe structure failure. But magnetite grains with fine cracks still existed (shown in Fig.5 (f)) as that of $550{ }^{\circ} \mathrm{C}$. So, the coarse cracks and fracted magnetite grains formed during reduction were the main cause for severe disintegration at $550{ }^{\circ} \mathrm{C}$. The disappearance of coarse 
crack at $600{ }^{\circ} \mathrm{C}$ eased the disintegration of pellets effectively.

\subsection{Effect of reducing gas}

Fig.6 showed the effect of reducing gas on reduction disintegration indexes (RDIs) of pellets. As demonstrated in the line chart, RDI increased steadily with the $\mathrm{H}_{2}$ proportion in reducing gas, reaching a peak of $1.9 \% \sim 3.1 \%$ (various with temperature) at $\mathrm{H}_{2} /\left(\mathrm{H}_{2}+\mathrm{CO}\right)=0.44\left(\mathrm{H}_{2} / \mathrm{CO}=0.8\right)$, then presented a downward trend to $\mathrm{H}_{2} /\left(\mathrm{H}_{2}+\mathrm{CO}\right)=1.0\left(\mathrm{H}_{2}\right.$ atmosphere). The RDI of pellets reduced by $\mathrm{CO}$ or $\mathrm{H}_{2}$ reached as low as $0.5 \%$.

Fig.6 Effect of reducing gas on reduction disintegration index,

$$
1-450{ }^{\circ} \mathrm{C}, 2-500{ }^{\circ} \mathrm{C}, 3-550{ }^{\circ} \mathrm{C}, 4-600{ }^{\circ} \mathrm{C}
$$

To understand the difference, reduction degree (RD) change of pellets with gas composition was examined as shown in Fig.7. To be specific, RD of pellet reduced by $\mathrm{CO}$ was $13.2 \%$ and this value reached the maximum of $20.5 \%$ at $\mathrm{H}_{2} / \mathrm{CO}=0.8$. Then RD gradually dropped down to $13.8 \%$ with the increase of $\mathrm{H}_{2}$ proportion in reducing gas. On one hand, due to the smaller molecular diameter the diffusion coefficient of $\mathrm{H}_{2}$ in pellet particles was three times higher than that of $\mathrm{CO}$ at $500{ }^{\circ} \mathrm{C}$ [29]. Thus $\mathrm{H}_{2}$ proportion increase could enhance the reduction process. On the other, excessive $\mathrm{H}_{2}$ proportion was unfavorable for the low temperature reduction of iron oxide because of its endothermic reaction characteristic [30]. The RD of pellet influenced by 
reducing gas corresponded well with its RDI variation tendency. That is, the higher $\mathrm{RD}$ of pellet led to a higher RDI for its more stress generation during reduction. This finding was in accordance with the reports of Taichi Murakami et al. [7].

Fig.7 Effect of reducing gas on the reduction degree of samples

Microstructure (cross section) of samples reduced by $\mathrm{CO}, \mathrm{H}_{2} / \mathrm{CO}=0.8$, $\mathrm{H}_{2} / \mathrm{CO}=1.6, \mathrm{H}_{2} / \mathrm{CO}=2.6, \mathrm{H}_{2}\left(\right.$ at $550{ }^{\circ} \mathrm{C}$ ) were characterized respectively, as shown in Fig. 8, to reveal the intrinsic influence of reducing gas.

Fig.8 SEM images of samples reduced with different reducing gases, $\mathrm{a}-\mathrm{CO}, \mathrm{b}-\mathrm{H}_{2} / \mathrm{CO}=0.8$, $c-\mathrm{H}_{2} / \mathrm{CO}=1.6, \mathrm{~d}-\mathrm{H}_{2} / \mathrm{CO}=2.6, \mathrm{e}-\mathrm{H}_{2}$

As presented in Fig. 8 (a), pellet that reduced by $\mathrm{CO}$ mainly kept the original structure except for a small amount of local failure. And pellet showed a low RDI value during reduction. However, the case differed obviously as pellets reduced by $\mathrm{H}_{2} / \mathrm{CO}=0.8$ or 1.6 . From Fig. 8 (b), coarse extensive cracks formed widely in pellet for the violent reduction therefore led to fragile structure and high RDI. Instead of coarse crack, numerous of criss-cross fine cracks produced by lattice transformation stress were found as pellet reduced in atmosphere of $\mathrm{H}_{2} / \mathrm{CO}=1.6$ (shown in Fig. 8 (c)). Cracks lessened and disappeared eventually with the further increase of $\mathrm{H}_{2}$ ratio in reducing gas as given in Fig. 8 (d) and (e). Besides RD difference discussed above (in Fig. 7), the reduction feature of $\mathrm{H}_{2}$ was considered to be another cause for this 
phenomenon. The strain level in magnetite crystal formed by $\mathrm{H}_{2}$ reduction was lower than that of $\mathrm{CO}$ because of the relatively uniform reduction of hematite $[12,13]$. Therefore, there was no stress concentration at surface and less structure failure generation in pellet, unlike during $\mathrm{CO}$ reduction.

\subsection{Effect of gangue}

In consideration of the possible influence of gangue on pellet disintegration, magnetite powder (analytical pure) was mixed with different proportions of $\mathrm{CaO}$, $\mathrm{MgO}, \mathrm{SiO}_{2}$ and $\mathrm{Al}_{2} \mathrm{O}_{3}$ (analytical pure) respectively based on Table 1. Then briquetting and oxidation roasting were carried out to prepare pellet according to our previous work [31]. Finally, the pellets were reduced at $550{ }^{\circ} \mathrm{C}$ with $\mathrm{H}_{2} / \mathrm{CO}=0.8$ atmosphere to investigate their RDIs as presented in Fig.9.

Fig.9 Effect of gangue on the reduction disintegration index, a-SiO ${ }_{2}, \mathrm{~b}-\mathrm{CaO}, \mathrm{c}-\mathrm{MgO}, \mathrm{d}-\mathrm{Al}_{2} \mathrm{O}_{3}$

It can be seen from the line chart that all the four usual gangue mentioned above could, to some extent, weaken the disintegration phenomenon. The disintegration of prepared pellets without any gangue composition was extremely serious $(\mathrm{RDI}=20.4 \%)$. From Fig.9 the RDIs declined sharply with $\mathrm{SiO}_{2}$ or $\mathrm{CaO}$ addition. As the content of $\mathrm{SiO}_{2}$ and $\mathrm{CaO}$ increased to $5.3 \%$ and $1.6 \%$, the RDIs of prepared pellets decreased to 9.8\% and 5.2\% respectively. However, there was only a minor drop of RDIs with $\mathrm{MgO}$ or $\mathrm{Al}_{2} \mathrm{O}_{3}$ addition. The RDIs of prepared pellets with $1.0 \% \mathrm{MgO}$ and $1.6 \%$ 
$\mathrm{Al}_{2} \mathrm{O}_{3}$ addition was still as high as $17.2 \%$ and $15.4 \%$ respectively. So, addition of $\mathrm{CaO}$ or $\mathrm{SiO}_{2}$ could weaken the pellet disintegration remarkably but effect of $\mathrm{MgO}$ or $\mathrm{Al}_{2} \mathrm{O}_{3}$ was inferior to the former.

Fig.10 Crack distribution in reduced compacts with $\mathrm{Al}_{2} \mathrm{O}_{3}$ (left) and $\mathrm{CaO}$ (right) addition

Cross section of reduced pellets with equal $\mathrm{Al}_{2} \mathrm{O}_{3}$ and $\mathrm{CaO}$ addition (1.6\%) were illustrated in Fig.10 to reveal this difference. Cross section of reduced pellets with equal $\mathrm{Al}_{2} \mathrm{O}_{3}$ and $\mathrm{CaO}$ addition (1.6\%) were illustrated in Fig.10 to reveal this difference. As can be seen, not only coarse cracks but also vast criss-cross fine cracks widely distributed in $\mathrm{Al}_{2} \mathrm{O}_{3}$ doped pellet. During reduction process, the coarse cracks broke integrated structure of pellet and the fine ones aggravated powder generation. However, few fine cracks could be observed in $\mathrm{CaO}$ doped pellet except for several coarse ones which probably ensured its less powder formation. This crack distribution difference also existed between $\mathrm{MgO}$ and $\mathrm{SiO}_{2}$ doped pellets. An electron microscopy equipped with image analysis system was employed to find the relation between gangue and crack distribution character. The area percentage occupied by cracks on cross section surface was given in Fig.11.

Fig.11 Effect of gangue on the crack distribution, $\mathrm{a}_{-\mathrm{SiO}}, \mathrm{b}-\mathrm{CaO}, \mathrm{c}-\mathrm{MgO}, \mathrm{d}-\mathrm{Al}_{2} \mathrm{O}_{3}$

As illustrated in Fig.11, the crack density of pellets formed during reduction varied with gangue addition apparently. The pellet prepared with no gangue addition 
showed high density of crack distribution (about $42.7 \% \cdot \mathrm{cm}^{-2}$ ) after reduction. $\mathrm{SiO}_{2}$ and $\mathrm{CaO}$ showed nice inhibition effect on crack formation. The crack distribution density of reduced pellets decreased to $10.4 \%$ and $13.6 \%$ respectively as $\mathrm{SiO}_{2}$ and $\mathrm{CaO}$ were doped in pure magnetite. However, this effect was not so obvious in $\mathrm{MgO}$ or $\mathrm{Al}_{2} \mathrm{O}_{3}$ doped pellets. The crack distribution density dropped slightly to $24.5 \%$ and $33.3 \%$ respectively. This variation tendency coincided well with their RDIs change as compared with Fig.9. That is, the more cracks formed during reduction process the higher RDI value of pellet would generate. The possible products formed by different gangue and magnetite during pellets preparation may be the cause for their crack diversity. The fayalite $\left(2 \mathrm{FeO} \cdot \mathrm{SiO}_{2}\right)$ and calcium ferrite $\left(\mathrm{CaO} \cdot \mathrm{Fe}_{2} \mathrm{O}_{3}\right)$ products with low melting point $[32,33]$ formed in $\mathrm{SiO}_{2}$ and $\mathrm{CaO}$ doped pellets may act as binder phase, which ensured their low disintegration during subsequent reduction. While such situation was almost absent in the case of $\mathrm{MgO}$ or $\mathrm{Al}_{2} \mathrm{O}_{3}$ addition.

\section{Conclusions}

In the present paper, disintegration behavior of iron ore pellet in simulated shaft furnace conditions was investigated in details. Disintegration was found to be most severe as pellet reduced by $\mathrm{H}_{2} / \mathrm{CO}=0.8$ at $550{ }^{\circ} \mathrm{C}$. Lattice transition $\left(\mathrm{Fe}_{2} \mathrm{O}_{3} \rightarrow \mathrm{Fe}_{3} \mathrm{O}_{4}\right)$ stress and crack generation brought about by the low temperature reduction were considered to be the main reason for pellet structure failure. The higher reduction degree of pellet reached the more failure and therefore disintegration would be. Gangue minerals in pellet were proved to ease the disintegration in various degrees. 
$\mathrm{SiO}_{2}$ or $\mathrm{CaO}$ could remarkably lower RDI for the low melting point phase $\left(2 \mathrm{FeO} \cdot \mathrm{SiO}_{2}\right.$ or $\mathrm{CaO} \cdot \mathrm{Fe}_{2} \mathrm{O}_{3}$ ) improved stress resistance of pellet. However, $\mathrm{MgO}$ or $\mathrm{Al}_{2} \mathrm{O}_{3}$ could not play a similar role.

\section{Acknowledgement}

Authors would like to express thanks to the National Science Foundation of China (Grant No. 51504230) for financial support of this research.

\section{References}

[1] Tooru Matsumiya, Steelmaking technology for a sustainable society, CALPHAD 35 (2011) 627-635.

[2] Murakami Taichi, Kamiya Yousuke, Kodaira Takeyuki et al, Reduction disintegration behavior of iron ore sinter under high $\mathrm{H}_{2}$ and $\mathrm{H}_{2} \mathrm{O}$ conditions, ISIJ Int. 52 (2012) 1447-1453.

[3] Parisi Daniel R., Laborde Miguel A., Modeling of counter current moving bed gas-solid reactor used in direct reduction of iron ore, Chem. Eng. J. 104 (2004) 35-43.

[4] Y. Ma, J.-X. Zhu, Characterizing gas and solids distributors with heat transfer study in a gas-solids downer reactor, Chem. Eng. J. 72 (1999) 235-244.

[5] A. Ajbar, K. Alhumaizi, M. Soliman, Modelling and parametric studies of direct reduction reactor, Ironmak. Steelmak. 38 (2011) 401-411.

[6] Ranzani da Costa A., Wagner D., Patisson F., Modelling a new, low $\mathrm{CO}_{2}$ emissions, hydrogen steelmaking process, J. Clean. Prod. 46 (2013) 27-35.

[7] Murakami Taichi, Kodaira Takeyuki, Kasai Eiki, Reduction and disintegration behavior of 
sinter under $\mathrm{N}_{2}-\mathrm{CO}-\mathrm{CO}_{2}-\mathrm{H}_{2}-\mathrm{H}_{2} \mathrm{O}$ gas at $773 \mathrm{~K}$, ISIJ Int. 55 (2015) 1181-1187.

[8] Yu Zheng-wei, Li Guang-hui, Liu Chen et al, Comparison of reduction disintegration characteristics of $\mathrm{TiO}_{2}$-rich burdens prepared with sintering process and composite agglomeration process, Int. J. Min. Met. Mater. 23 (2016) 389-398.

[9] WU Sheng-li, LIU Xiao-qin, ZHOU Qi et al, Low temperature reduction degradation characteristics of sinter, pellet and lump ore, J. Iron Steel Res. Int. 18 (2011) 20-24.

[10] El-Geassy A. A., Gaseous reduction of $\mathrm{Fe}_{2} \mathrm{O}_{3}$ compacts at 600 to $1050{ }^{\circ} \mathrm{C}$, J. Mater. Sci. 21 (1986) 3889-3900.

[11] El-Geassy A. A., Nasr M. I., Hessien M. M., Effect of reducing gas on the volume change during reduct ion of iron oxide compacts, ISIJ Int. 36 (1996) 640-649.

[12] Lingyun Yi, Zhucheng Huang, Tao Jiang et al, Swelling behavior of iron ore pellet reduced by $\mathrm{H}_{2}$-CO mixtures, Powder Technol. 269 (2015) 290-295.

[13] Zhucheng Huang, Lingyun Yi, Tao Jiang, Mechanisms of strength decrease in the initial reduction of iron ore oxide pellets, Powder Technol. 221 (2012) 284-291.

[14] A. Tilland, J. Prieto, D. Petitjean et al, Study and analyses of a CLC oxygen carrier degradation mechanism in a fixed bed reactor, Chem. Eng. J. 302 (2016) 619-632.

[15] Murakami Taichi, Kodaira Takeyuki, Kasai Eiki, Effect of the reduction of calcium ferrite on disintegration behavior of sinter under high hydrogen atmosphere, ISIJ Int. 55 (2015) 1197-1205.

[16] I. Shigaki, M. Sawada, M. Maekawa et al, Fundamental study of size degradation mechanism of agglomerates during reduction, Trans. Iron Steel Inst. Jpn. 22 (1982) 838-847.

[17] I. Shigaki, M. Sawada, N. Gennai, Increase in low temperature reduction degradation of iron ore sinter due to hematite-alumina solid solution and columnar calcium ferrite, Trans. Iron Steel 
Inst. Jpn. 26 (1986) 503-511.

[18] Mikko Iljana, Antti Kemppainen, Timo Paananenb et al, Effect of adding limestone on the metallurgical properties of iron ore pellets, Int. J. Miner. Process. 141 (2015) 34-43.

[19] Umadevi T., Kumar P., Lobo N. F. et al, Influence of pellet basicity $\left(\mathrm{CaO} / \mathrm{SiO}_{2}\right)$ on iron ore pellet properties and microstructure, ISIJ Int. 51 (2011) 14-20.

[20] D. J. Jiang, M. G. He, Q. Gan et al, Effect of $\mathrm{FeO}$ on properties of high-basicity sinter, China Metall. 18 (2008) 14-18.

[21] N. J. Bristow, C. E. Loo, Sintering properties of iron ore mixes containing titanium, ISIJ Int. 32 (1992) 819-827.

[22] MU Lin, JIANG Xin, GAO Qiang-jian et al, Effect of hydrogen addition on low temperature metallurgical property of sinter, J. Iron Steel Res. Int. 19 (2012) 6-10.

[23] Jong Ryun Kim, H. S. Kang, Ho Jun Lee et al, Real-time microradiology of disintegration of iron ore sinters, Nucl. Instrum. Meth. B 199 (2003) 441-445.

[24] R.Z. Wang, Y.Q. Sun, Q. Lv et al, Research on low-chloride inhibitor of reduction disintegration index of vanadium-bearing titanomagnetite sinter, J. Hebei Unit. Univ. 35 (2013) $4-10$.

[25] H. L. Guo, B. S. Hu, Y. L. Gui, Behavior on blast furnace smelting process of chlorine in coal, China Metall. 20 (2010) 12-17.

[26] Yi Lingyun, Huang Zhucheng, Peng $\mathrm{Hu}$ et al, Action rules of $\mathrm{H}_{2}$ and $\mathrm{CO}$ in gas-based direct reduction of iron ore pellets, J. Cent. South Univ. 19 (2012) 2291-2296.

[27] Lingyun Yi, Zhucheng Huang, Tao Jiang, Sticking of iron ore pellets during reduction with hydrogen and carbon monoxide mixtures: Behavior and mechanism, Powder Technol. 235 (2013) 
1001-1007.

[28] Yi Lingyun, Huang Zhucheng, Li Tiehui et al, Sticking of iron ore pellets in direct reduction with hydrogen and carbon monoxide mixtures: Behavior and prevention, J. Cent. South Univ. 21 (2014) 506-510.

[29] Yoshihito Shigeno, Takayuki Sakakibara, Yasuo Omori, In Situ measurement of effective gas diffusivity through hematite pellets during stepwise reductions, Metall. Mater. Trans. B 21B (1990) $677-687$.

[30] Huang Xiku, Principles of ferrous metallurgy, third ed., Metallurgical Industry Press, Beijing, 2005.

[31] Huang Zhucheng, Yi Lingyun, Peng Hu et al, Effects of roast temperature on properties of oxide pellets and its gas-based direct reduction, J. Cent. South Univ. (Sci. Technol.) 43 (2012) 2889-2895.

[32] Webster A. S., Pownceby M. I., Madsen I. C. et al, Silico-ferrite of calcium and aluminum (SFCA) iron ore sinter bonding phases: new insights into their formation during heating and cooling, Mater. Trans. B 43B (2012) 1344-1357.

[33] Webster A. S., Pownceby M. I., Madsen I. C. et al, Fundamentals of silico-ferrite of calcium and aluminum (SFCA) and SFCA-I iron ore sinter bonding phase formation: effects of $\mathrm{CaO}: \mathrm{SiO}_{2}$ ratio, Metallurgical Mater. Trans. B 45B (2014) 2097-2105. 


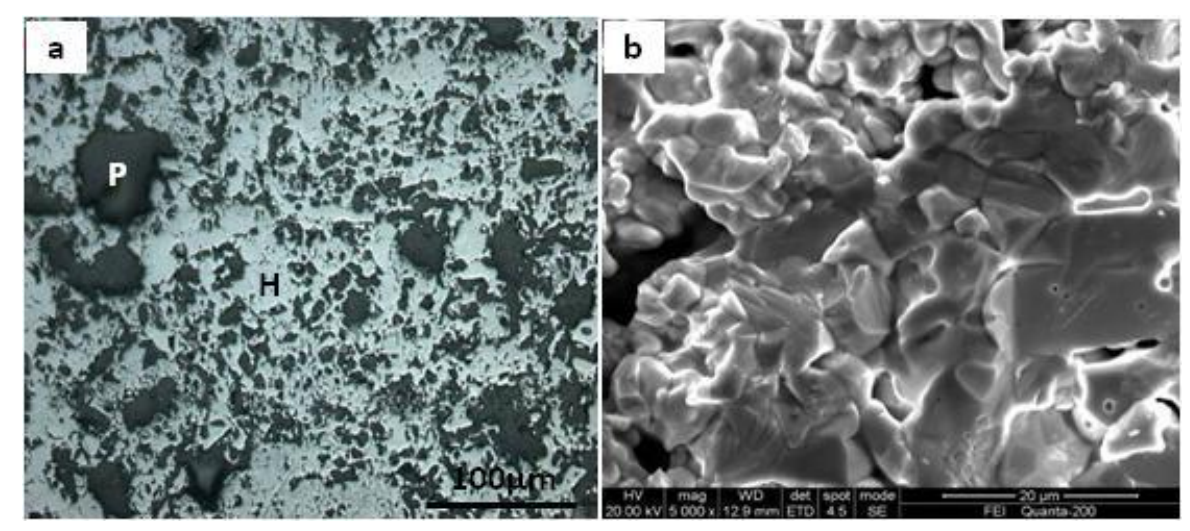

Fig.1 


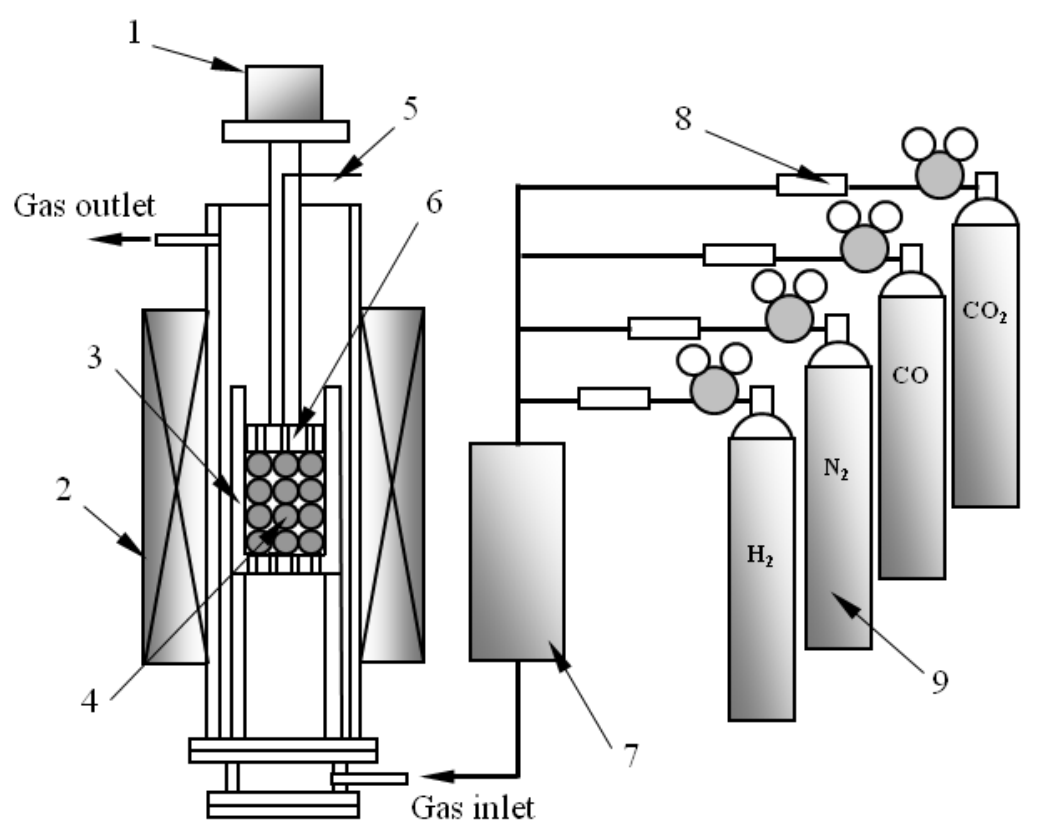

Fig.2 


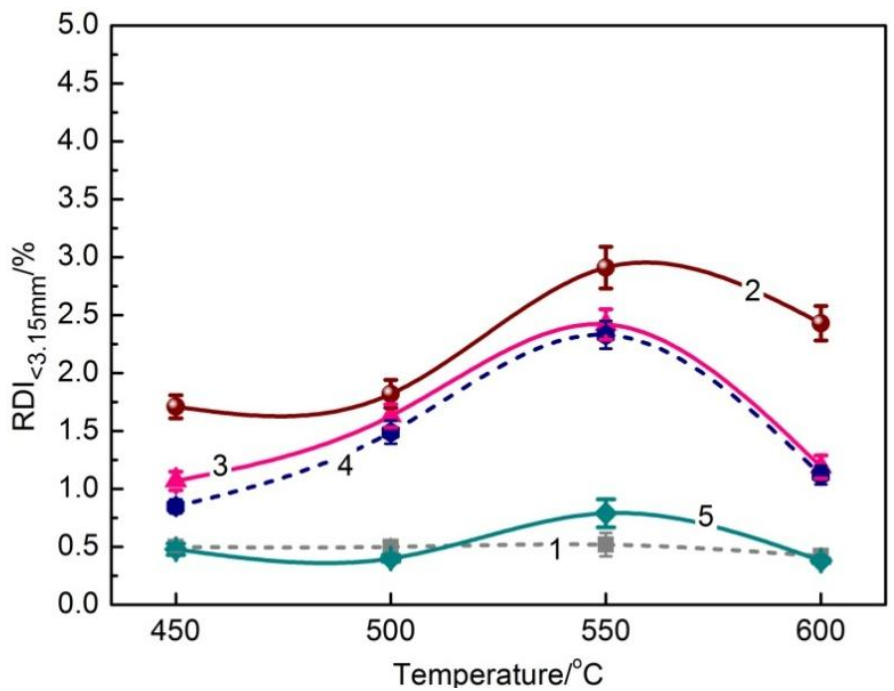

Fig.3 


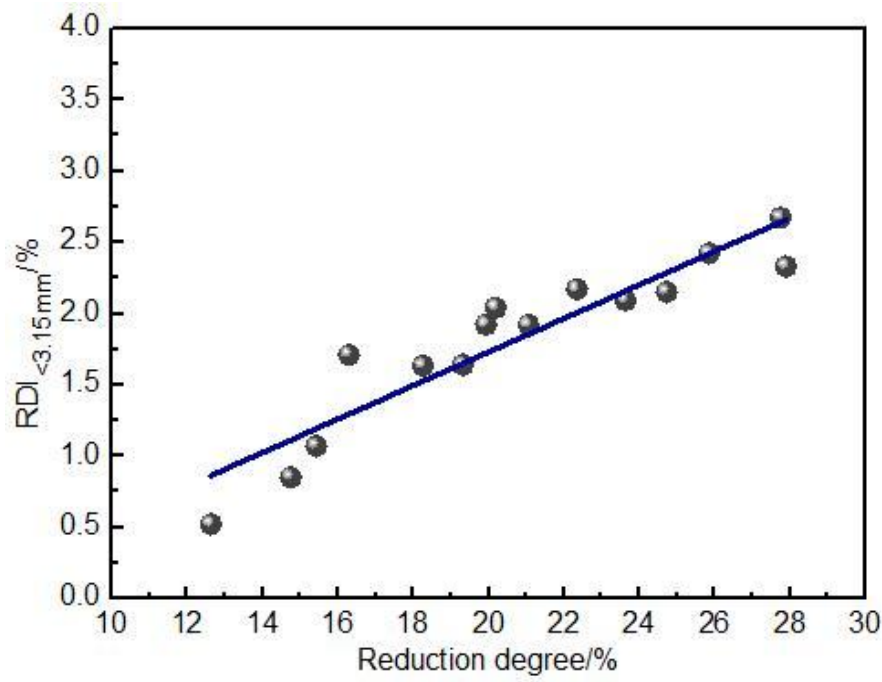

Fig.4 

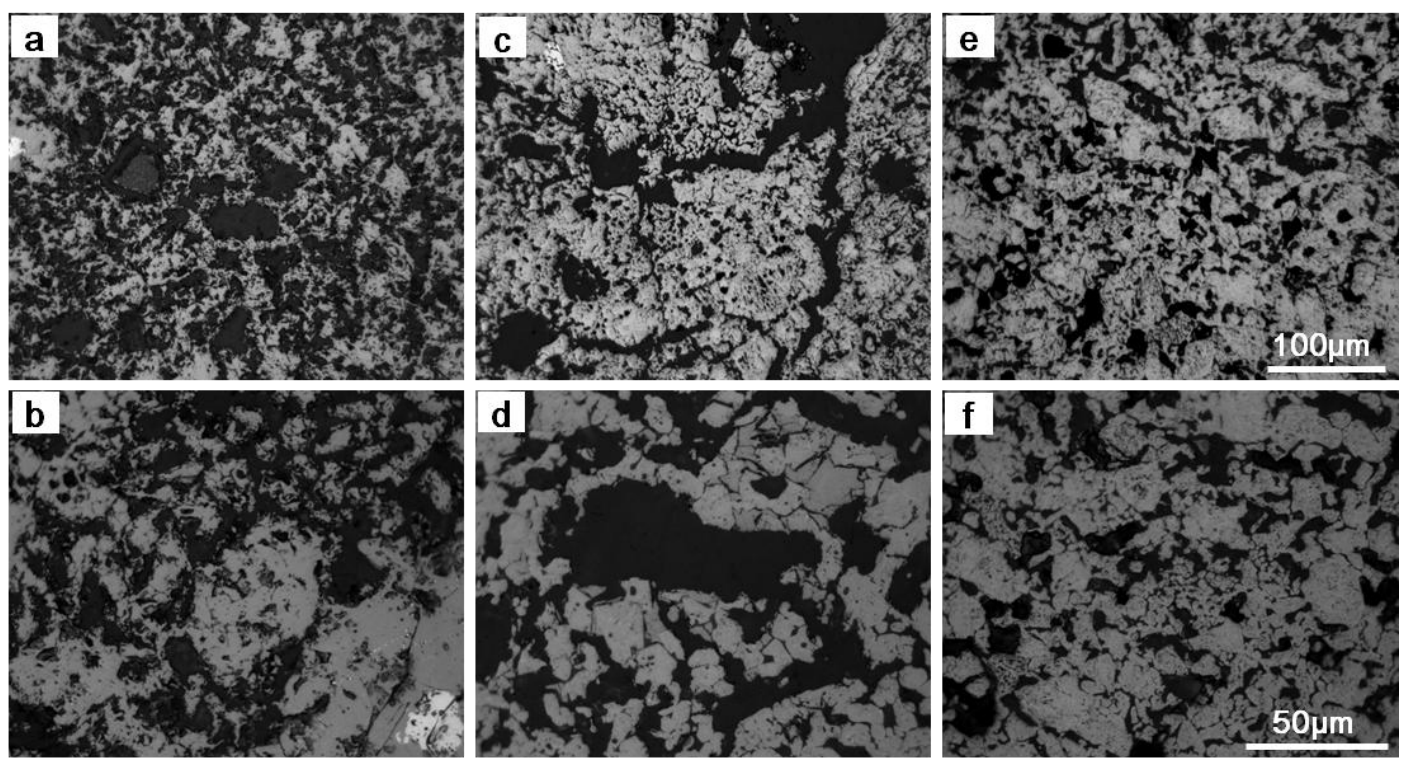

Fig.5

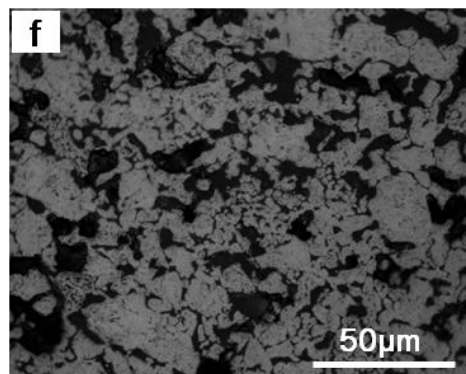




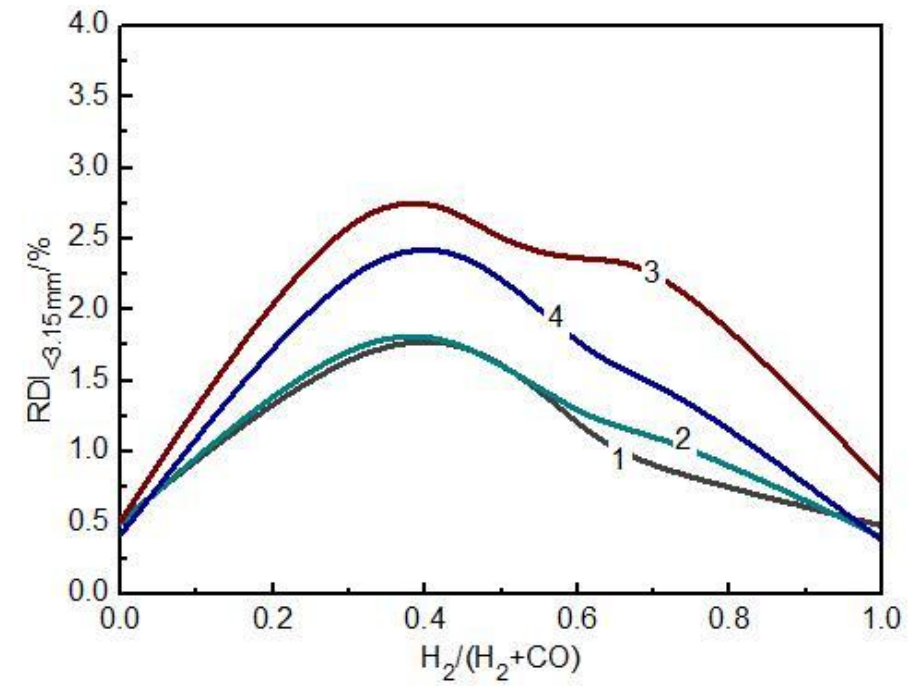

Fig.6 


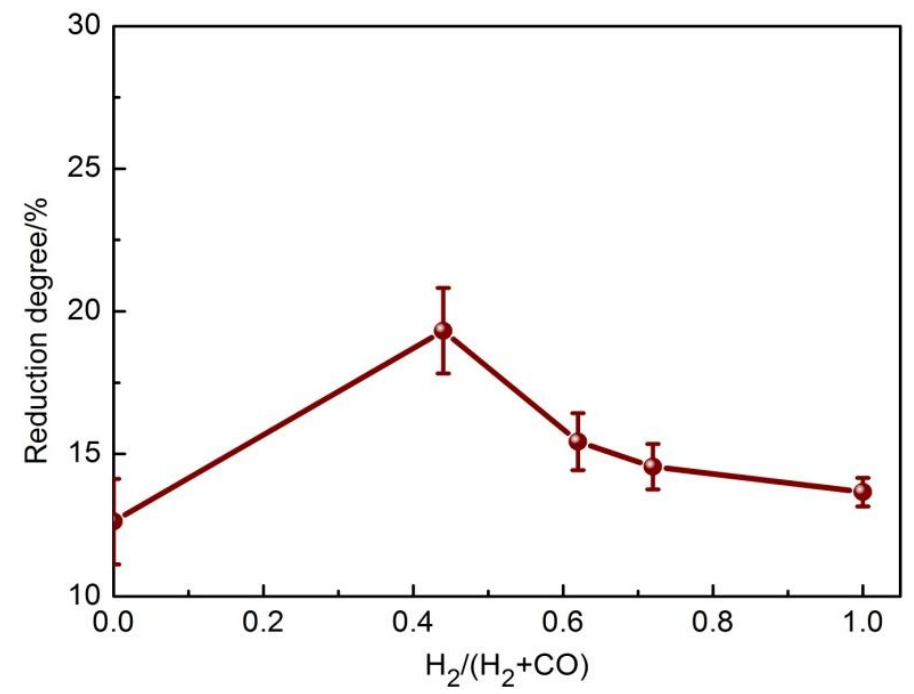

Fig.7 


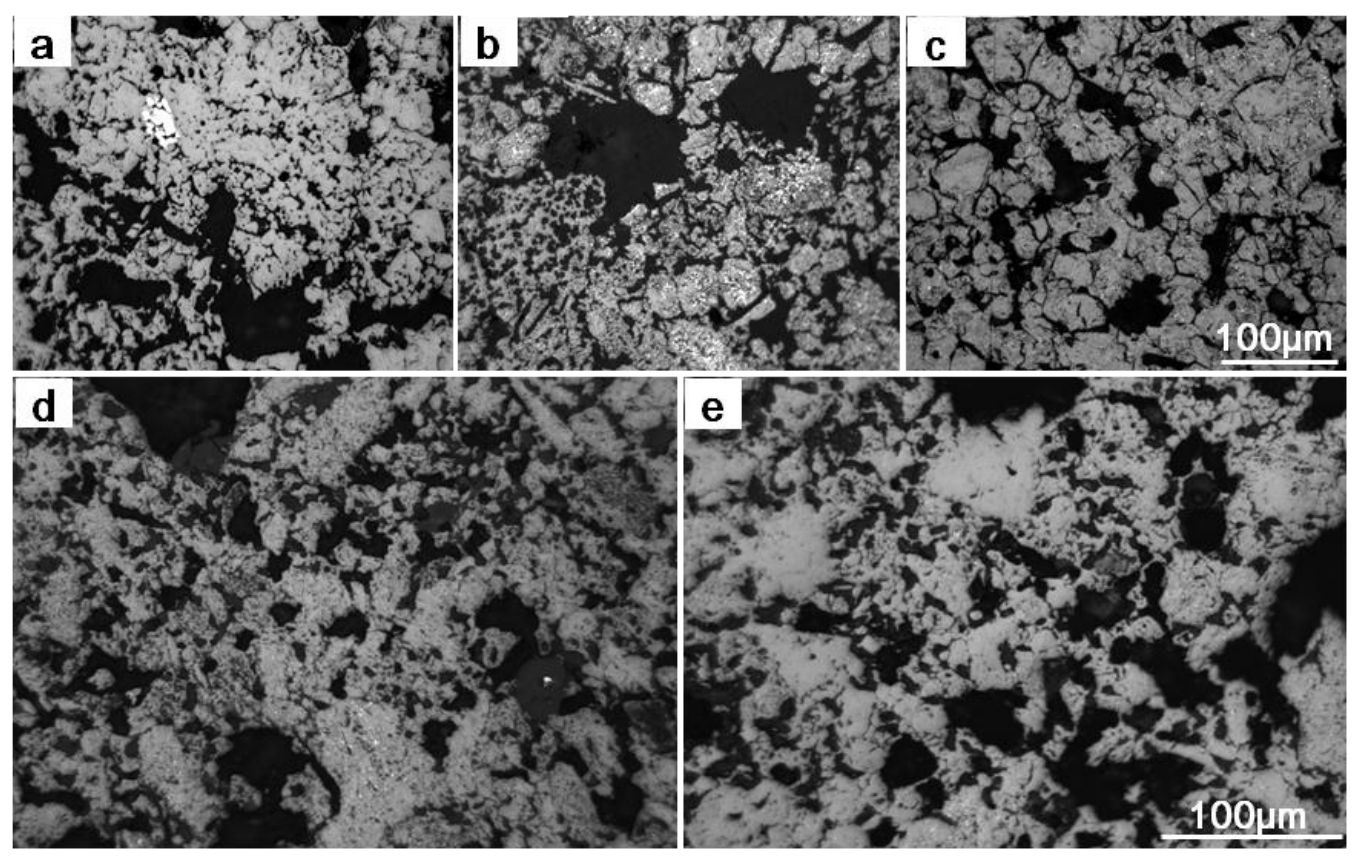

Fig.8 


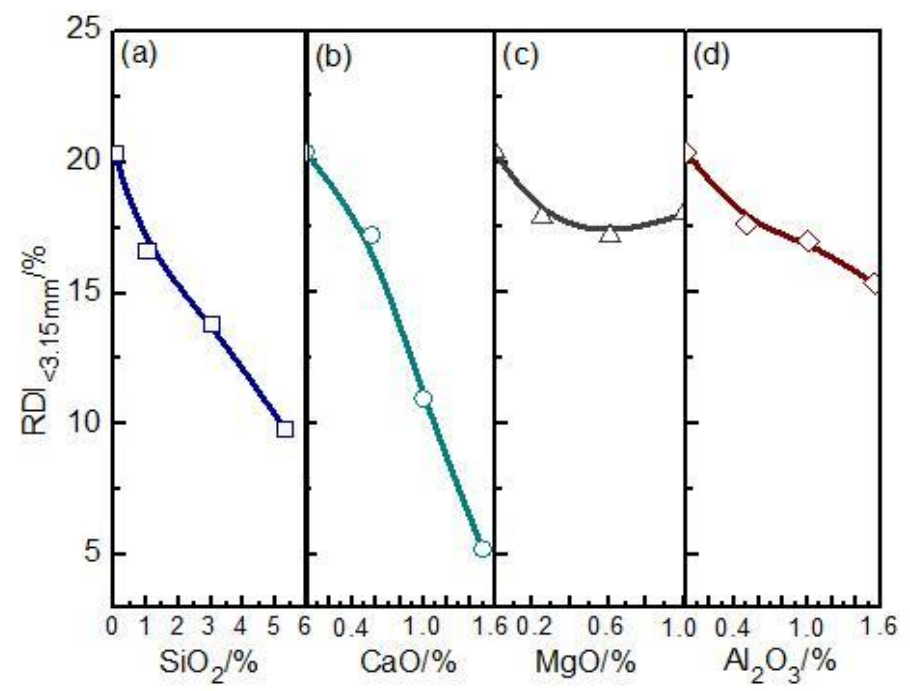

Fig.9 


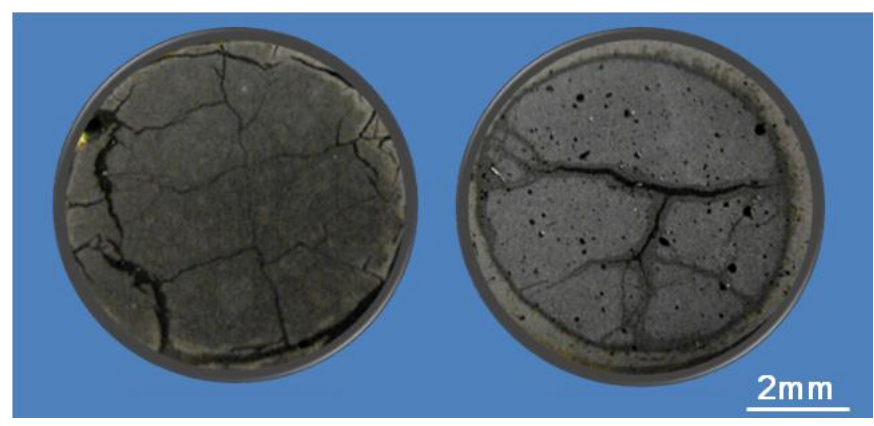

Fig.10 


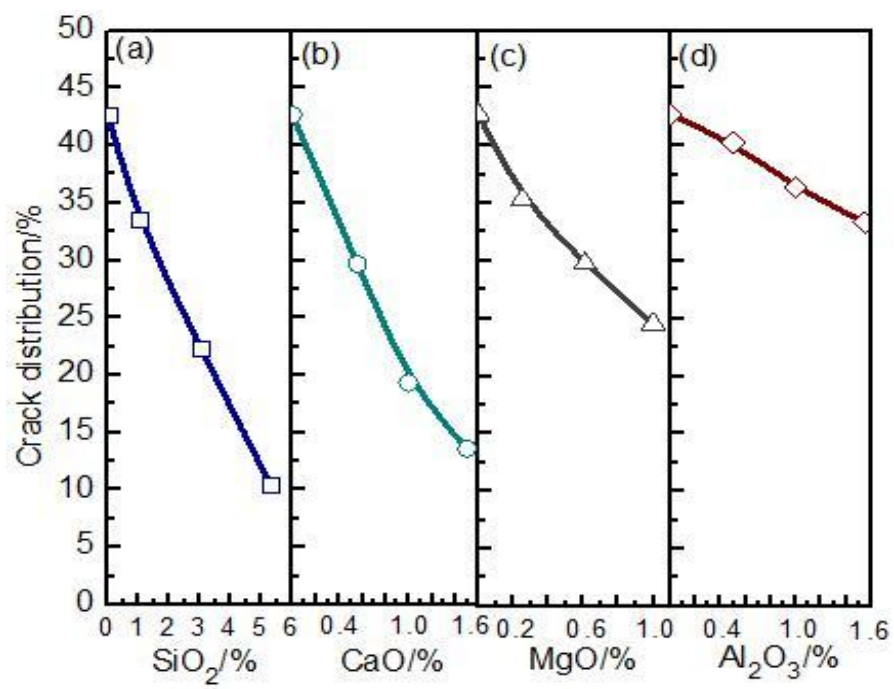

Fig.11 


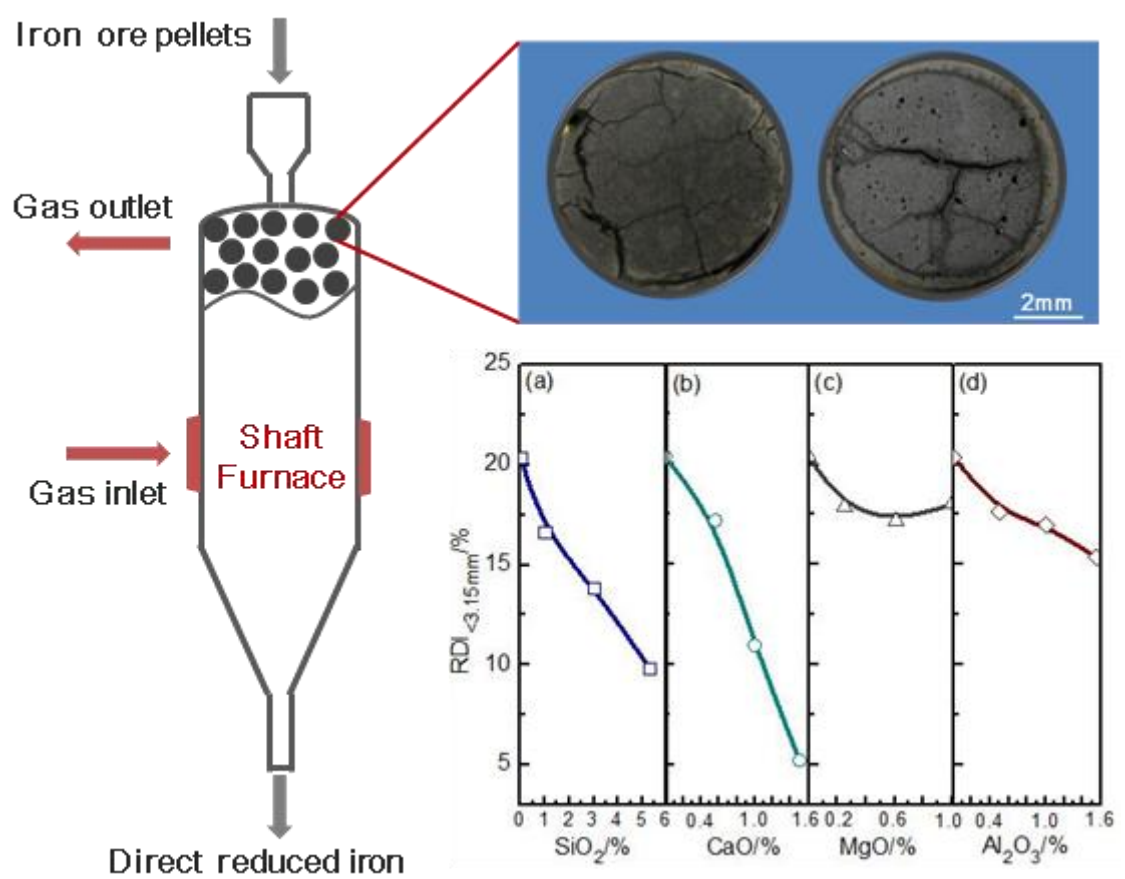

